\title{
Les compilacions valencianes durant l'edat moderna
}

\author{
Francisco Javier Palao Gil (palao@uv.es) \\ Universitat de València
}

\section{Les compilacions publicades (1482-1548)}

La història de les compilacions ${ }^{1}$ del dret foral valencià és coneguda i ha estat estudiada per molts investigadors (Peset, 1971: 47-84; García Edo, Graullera i Bas, 2002: 15-83). Des del final del segle xv, i fins a la seua abolició després del decret de 29 de juny de 1707 , el nostre dret històric va conéixer tres recopilacions impreses i una altra que va quedar manuscrita. La primera va ser la cronològica de final del segle xv, obra del notari i justícia de València Gabriel Lluís d'Arinyó (1482) —en la qual també va col·laborar un altre notari, misser Gabriel Riusech-, impresa amb gran perfecció per Lambert Palmart; la seua tècnica compiladora era senzilla: al principi es van col·locar els furs atorgats per Jaume I i a continuació els promulgats pels seus successors en ordre estrictament cronològic fins a les Corts de València de 1446, seguint la data de les reunions en què s'havien donat. L'obra es tancava amb uns materials del mateix any de 1446, l'Stil de la Governació d'Arnau Joan, un petit tractat sobre l'estructura política del regne, que certament no s'ajustava massa als treballs propis d'una recopilació; també s'hi incloïen diverses sentències, pragmàtiques i provisions de caràcter processal, fins i tot l'anomenada «Concòrdia de la reina Leonor»... Així mateix, altres errors palesen la imperfecció d'una tècnica que estava en els inicis: els furs d'Alfons IV precedeixen els dels seus antecessors; les primeres lleis s'ordenen per rúbriques, però a partir de les de Pere IV es col·loquen per dates; s'hi recullen disposicions molt variades sense fer la distinció deguda entre furs, capítols, provisions i ordenances, etc.

Tres dècades més tard es portava a la premsa una recopilació dels privilegis de la ciutat i el Regne de València, l'Aureum Opus Regalium Privilegiorum Civitatis et Regni Valentiae, que era també obra privada d'un notari, Lluís d'Alanyà (1515), qui va utilitzar velles col·leccions i va seleccionar, seguint un ordre estrictament cronològic, els preceptes més notables o generals. Venia així a completar l'edició prínceps del 1482, atés que el dret reial no s'exhauria amb el que es promulgava en les Corts, sinó que també els privilegis tenien un especial relleu jurídic.

Finalment, a mitjan segle XVI culminaria el moviment compilador a terres valencianes. La situació semblava propícia, ja que l'edició prínceps de 1482 havia quedat antiquada per la successió de reunions de Corts des de la ja llunyana de 1443-1446: almenys unes altres set n'havien seguit i els seus furs i capítols, nombrosos, esperaven a ser compilats per tal de facilitar-ne la consulta. A més, la tècnica recopiladora experimentava una millora manifesta

\footnotetext{
${ }^{1}$ Al llarg del treball emprarem de manera indistinta els conceptes de «recopilació» i «compilació» — que seria el terme més adient i genuí en la nostra llengua per a fer referència a la matèria ací tractada.
} 
i començaven a imposar-se les tendències sistematitzadores que permetien superar el criteri cronològic, tan incòmode per a la consulta i inapropiat per a l'estudi del jurista: les lleis s'ordenen ara per matèries, la qual cosa permet manejar-les millor i comparar les que regulen una mateixa institució, detectant incoherències, errades o derogacions tàcites... Lluís d'Alanyà va deixar preparat, cap al 1544, un text sobre el qual laborà un altre notari, Francesc Joan Pastor (1547-1548), amb l'ajuda del doctor Pere Joan Capdevila, catedràtic de dret civil i advocat. Els jurats i el Consell de la ciutat van donar suport a l'edició.

El resultat va ser l'edició en 1547-1548 dels Fori Regni Valentiae, una recopilació sistemàtica de la legislació emanada de les Corts del regne. Per a ordenar i colllocar els nous materials, Pastor va utilitzar els llibres i rúbriques en què es dividien els Furs de Jaume I, derivats, al cap i a la fi, del Codex de Justinià, i es va servir d'ells a manera de «casellers», com els anomenà fa més de tres dècades, d'una forma molt gràfica, el professor Peset (1971: 68). No obstant això, moltes de les disposicions no trobaren acomodament en la vella estructura romana i va ser necessari compondre un segon volum amb les normes que no cabien en la part sistemàtica. Aquest volum, dit d'«Extravagants», va recollir, en ordre cronològic, furs relatius a l'organització del regne i dels municipis, a procediments de tipus molt divers o a supòsits d'índole personal o particular; però també s'hi van incloure altres materials sense rang de furs i de caràcter variat: pragmàtiques, ordinacions, provisions $i$ fins i tot l'Stil d'Arnau Joan. Capdevila corregí i anotà l'obra amb un aparell de glosses que concordaven el seu contingut amb el dret comú i els privilegis del regne; a més, el bon coneixement que tenia de l'ordenament romà el va portar a estructurar la compilació seguint el model del Codex de Justinià (Febrer, 2000a: 48-49; 2000b: 198-199).

L'edició reuní la legislació foral fins a les Corts de 1542, d'una forma sistemàtica però amb una exegesi deficient, ja que no hi hagué un control sobre la vigència o no dels textos, les reiteracions i les llacunes o les contradiccions entre les normes inserides. Però, més enllà de les seues imperfeccions - que les té-, la recopilació de Pastor va posar a l'abast dels juristes la part principal del dret foral valencià organitzada de manera sistemàtica, la qual cosa suposà un avanç indubtable. D'altra banda, com ja assenyalà el professor Peset (1971: 68-69), la de Pastor és una obra privada, sense caràcter oficial. La presència en la portada del privilegi imperial que concedí el príncep Felip amb motiu de les Corts de Montsó de 1547 va induir el professor Tomás y Valiente (1986: 277), de manera errònia, a atorgar a la recopilació un valor oficial. Però no hi hagué cap fur o privilegi reial que sancionara l'obra. De forma resumida, es pot afirmar que es tracta del treball d'un pràctic del dret bon sabedor del dret foral i interessat pels problemes que plantejava el seu coneixement més precís, un element més a la disposició dels juristes per tal de concretar de forma homogènia les seues al-legacions i demandes.

\section{Els intents de promulgar una compilació oficial (1548-1665)}

La necessitat de disposar d'una recopilació oficial anirà obrint-se camí al llarg dels anys següents. Les Corts de Montsó de 1564 van ser el primer pas. ${ }^{2}$ Els braços plantejaren

\footnotetext{
${ }^{2}$ Furs, capítols, provisions, e actes de cort, fets y atorgats per la S.C.R.M. del Rey Don Phelip nostre senyor (...) en les Corts generals per aquell celebrades als regnícols de la Ciutat y Regne de València, en la vila de Monçó, en lo any MDLXIIII, cap. CXLII, f. $22 \mathrm{r}$ i v.
} 
llavors un nou volum dels Furs que corregira els errors tan habituals en les edicions i recopilacions de l'època: furs derogats o no atorgats, repetits i superflus, omesos, amb reproducció incorrecta de termes, etc. S'hi assenyalà especialment la impressió de Pastor, en la qual «hi ha moltes errors» — un fet que, d'una altra banda, en mostra el relleu a penes quinze anys després d'impresa-. Es proposà una comissió àmplia, amb dos electes per cada braç, juntament amb els síndics i advocats dels estaments, l'assessor de la Generalitat i un notari. El rei assentí amb la condició que hi intervinguera el seu fiscal. L'obra, sens dubte, hauria tingut un caràcter oficial, amb el suport del regne a través dels braços o estaments, i del monarca. No s'ha d'oblidar que en aquests mateixos anys Catalunya i Aragó pretenien també completar i perfeccionar les recopilacions respectives. Catalunya va insistir en diverses reunions - en aquestes mateixes Corts de Montsó, per exemple - fins a aconseguir una edició oficial en 1588-1589, molt millorada si la comparem amb la impresa en 1495 (Oleart, 2004: 223-286). Aragó ja havia publicat una col-lecció oficial, sistemàtica, en 1552: Fueros y Observancias de Aragón. Així, davant l'avanç de la legislació reial, els regnes de la Corona tendien a ordenar les seues normes i editar-les, si era possible amb el reconeixement del sobirà, i València no volgué quedar-se arrere.

El capítol mencionat de 1564 donava alguna pista sobre la tècnica que es pretenia, collocant els furs nous en els títols i rúbriques corresponents per la matèria segons l'ordre de les edicions antigues —és a dir, seguint l'establit per Jaume I- També s'hi suggeria la possibilitat de fer quaderns o llibres diferents per als actes de Cort dels braços i per a les normes revocades o derogades, en desús i «de les altres coses poch importants». La tècnica era, doncs, la mateixa que havia utilitzat Pastor, encara que amb la millora dels quaderns separats, que superava, per l'ordre i la jerarquia, la del volum d'Extravagants. En la línia de les recopilacions aragoneses, es pretenia la fidelitat al text i la conservació dels materials antics, tot i que fora en un llibre separat.

En 1571 Pere Jeroni Tarazona començaria a treballar en la recopilació, una labor que li portaria més de quatre anys de faena intensa. El mateix Tarazona (1580: 5v) descriví les dificultats que va trobar en assenyalar que: «aprés de començada de moltes maneres, em resolguí en què, per a fer-la de la manera que convé, tenia necessitat de summar tots los dits Furs». En acabar el seu treball, sol-licità que es nomenaren cinc doctors perquè l'examinaren i l'aprovaren. Però, encara que van ser nomenats, mai va aconseguir que feren l'examen, de manera que la recopilació no va arribar a veure la llum. El mateix Tarazona va ser nomenat assessor de la Governació dellà Xixona, la qual cosa li va impedir completar alguns dels treballs que tenia en marxa arran de les tasques de la recopilació. Entre els esborranys que confeccionà, va utilitzar el que col-leccionava les institucions jurídiques contingudes en els furs i privilegis per a publicar la seua obra mestra: les Institucions. Tarazona va decidir conservar aquells esborranys fins que el rei convocara novament les Corts, «segons de pròxim se esperava», i n'impulsara definitivament l'edició. ${ }^{3}$

No obstant això, caldria esperar a la reunió de 1604 a València perquè els braços tornaren a fer una petició en el mateix sentit. ${ }^{4}$ Les Corts partien de la base del que s'havia

\footnotetext{
${ }^{3}$ A Catalunya trobem el mateix problema: les Corts van impulsar els treballs fins a l'obtenció d'un text complet; però, encara que se'n va remetre al monarca per a l'aprovació, mai no l'obtingué (Oleart, 2004: 227232).

4 Furs, capítols, provisions, e actes de cort, fets y atorgats per la S.C.R.M. del Rey Don Phelip nostre senyor (...) en les Corts generals per aquell celebrades als regnícols de la Ciutat y Regne de València, en lo monestir
} 
determinat en 1564 i aprofitaren en aquesta ocasió el treball de dos doctors en dret, Josep Ferriol i Joan Baptista Trilles, ${ }^{5}$ que «han fet grans diligències en la reducció de dits furs, i en fer un nou volum de aquells, posant-los sub congruis titulis». La tècnica era la mateixa que llavors: situar els furs nous en les rúbriques corresponents de les antigues edicions. S'hi establia en aquest cas un requisit nou: la supervisió prèvia per part dels advocats dels braços per a comprovar la utilitat - i cal imaginar que també la idoneïtat tècnica- del nou volum. Els costos del treball i la impremta correrien per compte del regne, a través de la Generalitat. Però tampoc en aquest cas es va avançar finalment en una nova recopilació.

Les Corts valencianes tornarien a plantejar el problema de la recopilació en la reunió convocada per Felip IV en 1626 a Montsó, ${ }^{6}$ encara que aquesta vegada en termes més modests. L'acumulació de reunions de Corts sense compilar - quatre des de 1547començava a causar dificultats en la consulta dels furs i capítols a través dels quaderns impresos. Ja no s'hi troben referències als defectes de la recopilació de Pastor i a la necessitat de renovar-ne el text. Ni tan sols es proposen les persones que han d'assumir la tasca, atés que la designació es deixa en mans del rei. En tot cas, sí que es plantejava l'elaboració d'una obra de caràcter general, ja que es demanava «fer nova recopilació (...) de tots los furs y actes de Cort de dit Regne ab ses rúbriques i títols».

Però en realitat, el camí cap a l'edició d'una nova recopilació valenciana no es reprendria fins tres dècades més tard, quan el 30 de juny de 1656 el Consell d'Aragó ordenà escriure al virrei, el duc de Montalto, una carta amb una reproducció del fur 41 d'aquelles Corts de 1626, per tal que tractara l'assumpte amb els diputats del regne i es decidira conjuntament la persona a qui es podria encarregar l'obra. ${ }^{7}$ El virrei contestà amb una terna de noms - els candidats per a fer la compilació - de collita pròpia, on figurava en primer lloc el paborde Maties Morlà, «que tengo entendido haver hecho algún trabaxo en la materia». Poc després, el 6 d'agost, Morlà era designat pel Consell d'Aragó, amb la condició que el seu treball fora supervisat per l'oïdor de l'Audiència Cosme Gombau. ${ }^{8}$ El paborde Morlà era un doctor en dret no massa conegut, que havia obtingut en 1640 la pabordia primera de Lleis en l'Estudi General de València i que va servir la càtedra de manera ininterrompuda fins que en 1658 va ser nomenat assessor de la cort del batle general del Regne de València, ofici que exercí fins al 1666, data probable de la seua mort. No va ser un autor prolífic, ja que sembla que al llarg de la vida no va escriure molt més que algunes al-legacions jurídiques usuals i pròpies del seu ofici, així com alguns versos en ocasions solemnes. ${ }^{9}$

del gloriós Sanct Domingo del Orde de Predicadors de la dita ciutat de València, en lo any MDCIIII, cap. CCXLVI, f. $45 \mathrm{v}^{\circ}$.

${ }^{5}$ Potser és Trilles el més conegut dels dos, per la seua llarga carrera com a advocat fiscal, de vegades al servei d'institucions com el municipi del Cap i Casal. En els últims anys de la vida va ser jutge de cort i oïdor de l'Audiència de València. De tota manera, no sembla que el treball recopilatori que van realitzar es plasmara, com el de Tarazona, en una obra impresa.

${ }^{6}$ Furs, capitols, provisions, e actes de cort, fets y atorgats per la S.C.R.M. del Rey Don Phelip nostre senyor (...) en les Corts generals per aquell celebrades als regnícols de la Ciutat y Regne de València, en la vila de Monçó, en lo any M.DC.XXVI, cap. XLI, f. $14 \mathrm{v}^{\circ}$.

${ }^{7}$ Arxiu de la Corona d'Aragó, d'ara en avant ACA, Consell d’Aragó, lligall núm. 903, exped. núm. 14.

${ }^{8}$ ACA, Consell d’Aragó, lligall núm. 770, exped. núm. 4.

${ }^{9}$ Les dades sobre la carrera universitària de Morlà són recollides per Amparo Felipo (1991: 356, 449450) i Vicent Graullera (2003: 105, 259). Es conserven igualment algunes al-legacions jurídiques impreses tant de l'època en què va exercir la pabordia com del temps en què va ser assessor de la Batlia General. 
El 12 de setembre de 1656 Maties Morlà escrigué al vicecanceller d'Aragó per a acceptar-ne l'encàrrec i també l'ordre que havia d'observar en la recopilació. Així, algun temps després el paborde lliurà un document amb les directrius generals del treball que mamprendria. En l'esmentat document feia un inventari de les rúbriques existents en l'edició impresa de Francesc Joan Pastor, de 1547, amb algunes vacil·lacions i errors; a continuació proposava extraure d'una banda els furs i actes de Cort que podien situar-se en les rúbriques ja existents, mentre que amb aquells per als quals no trobara acomodament compondria l'apartat habitual d'Extravagants. ${ }^{10}$ No trobem, doncs, variació ni innovació respecte al mètode de Pastor per a formar la recopilació de 15471548. La sistemàtica era tan senzilla que Morlà va arribar a plantejar la possibilitat de fer una edició limitada a un volum comprensiu de les noves lleis promulgades per les Corts des de 1547, però el Consell desestimà la proposta en recordar-li que el fur de 1626 exigia una compilació completa i nova.

Encara que Maties Morlà va progressar en la tasca compiladora, tres anys després el Consell tornava a demanar al nou virrei, el marqués de Camarasa, notícia dels avanços, ja que no havia arribat a la cort reial cap tipus d'informació sobre aquella qüestió. El paborde reconegué que havia patit una llarga malaltia, però que havia assabentat del fet el vicecanceller i que després havia continuat el treball tot ajustant-se al mètode que li havia estat aprovat, de manera que l'havia avançat fins a arribar a les Corts de l'any 1585, colllocant els furs en els títols i rúbriques dels nou llibres del primer volum de la recopilació de Pastor. Ara bé, començava a trobar problemes amb els que no tenien entrada en els epígrafs tradicionals, ja que «se an de colocar, después bajo de otros títulos que se an de sacar de los digestos u del código, como se lo tiene advertido el vicecanciller». Cosme Gombau, per la seua part, es limità a afegir que comprovava periòdicament que el treball de Morlà s'ajustava al pla compilador. ${ }^{11}$ Però, a l'abril de 1661 el vicecanceller del Consell d'Aragó tornà a inquirir per l'excessiva dilació que començaven a acumular els treballs de la compilació i Morlà s'excusà al-legant que li havia calgut dedicar-se a altres assumptes. ${ }^{12}$ A instància del virrei, accedí a comprometre's a acabar el treball davall la supervisió de l'oïdor Gombau, però amb poc d'èxit, segurament per la manca de finançament. Així, un any després, el Consell demanava de nou al virrei que informara sobre la compilació, tot amenaçant de substituir Morlà per un altre si no la concloïa amb brevetat. Aquest tractà de defensar-se explicant el progrés del seu treball, però el Consell ja no se'n fiava: «ha muchos años que dize esto el Doctor Morlà y que no se sabe haya adelantado más la materia de lo que ahora refiere». I per aquesta raó ordenà al virrei que Morlà mostrara al regent de l'Audiència tot el que havia fet fins a aquell moment, donant compte després dels avanços produïts. ${ }^{13}$

\footnotetext{
${ }^{10}$ «Breve Resumen del Método y disposición que pertenece a la Recopilación que la Magestad del Rey nuestro señor ha mandado que ordene el Pavordre Mathías Morlá», Arxiu del Regne de València, d'ara en avant ARV, Varia, 1ligalls, caixa núm. 5, exped. núm. 11 (vegeu F. J. Palao, 2007: 359-368, amb la transcripció completa del text).

${ }^{11}$ Cartes de juny de 1659 en ACA, Consell d’Aragó, lligall núm. 743, exped. núm. 57.

${ }^{12}$ El paborde es queixava, i amb raó, d'haver deixat 8.000 ducats en propietat en la càtedra i 1.000 més com a assessor de la Diputació per a servir un ofici improductiu.

${ }^{13}$ Carta de juny de 1662 en ACA, Consell d’Aragó, lligall núm. 753, exped. núm. 22.
} 
Tot i això, la reiteració no produí els efectes desitjats. A l'estiu de 1664 els consellers recordaven que la compilació ja portava un recorregut de huit anys i que la paciència se'ls acabava. Continuaven exigint que el paborde «cumpla al tiempo señalado con la recopilación de los fueros, $\mathrm{o}$ antes si fuere posible $\aleph^{14} \mathrm{i}$ li donaven sis mesos més, transcorreguts els quals hauria de lliurar els seus papers per tal que el monarca, si no estava acabada, l'encarregara a un altre. ${ }^{15}$ El virrei cridà immediatament Morlà, qui va explicar que ja tenia fetes dues terceres parts de la faena i que esperava completar-la abans del termini de sis mesos si s'ordenava al regent de l'Audiència que l'ajudara en la collocació d'alguns furs. Tot i això, a la mort de Felip IV al setembre de 1665, el treball continuava detingut.

\section{La compilació inèdita (1665-1702)}

Possiblement, el Consell estava buscant un substitut per al paborde, que va morir un any després. La identitat del substitut no és segura. Just Pastor Fuster (1827), en la seua Biblioteca Valenciana, reprodueix una carta del doctor Isidor Aparici Gilart, antic oïdor de l'Audiència i mà dreta de l'arquebisbe fra Joan Tomàs de Rocabertí, al virrei comte d'Altamira, en què es parla de l'assumpte. ${ }^{16}$ Aparici cita en primer lloc Llorenç Mateu i Sanz, que l'any 1667 es trobava ja a Madrid com a «alcalde de casa y corte», i que poc després obtindria la plaça de fiscal del Consell d'Índies; però no tenim cap notícia sobre un eventual encàrrec, a més que no presenta el perfil adient per al treball, atés que era un alt magistrat al servei de la monarquia. ${ }^{17}$ Després fa esment del doctor Joan Baptista Bravo i del Vado, el protagonisme del qual sí que ve confirmat per la documentació d'arxiu. Entre els anys 1685 i 1686 aquest advocat valencià, que aleshores ja estava retirat per una ceguesa progressiva, tractà d'obtindre alguna mercé - una plaça de cavaller amb vot en Corts, juntament amb la coadjutoria de mestre racional o una escrivania de manament en l'Audiència-, i a tal fi va exposar els mèrits contrets al llarg de vora dues dècades de treballs en la recopilació dels furs que Maties Morlà no havia arribat a acabar. En l'escrit feia un repàs de la trajectòria de la compilació des que el rei i els braços de les Corts havien acordat que s'elaborara en 1564. Ell es trobava a Madrid des de 1665, quan havia arribat de València per a colllaborar en els plets que la capital sostenia amb el duc de Sogorb; posteriorment es convertiria en advocat de la ciutat de València a la cort reial ${ }^{18}$. En aquest sentit, podríem datar l'encàrrec a Bravo i del Vado entre els anys 1667 i 1669, molt possiblement coincidint amb el seu nomenament com a lletrat

\footnotetext{
${ }^{14}$ Carta del Consell d'Aragó al marqués d'Astorga, virrei, del 27 d'agost de 1664, i contestació del 2 de setembre, en ACA, Consell d'Aragó, lligall núm. 761, exped. núm. 100.

${ }^{15}$ En aquest cas la carta reial és del 12 d'agost de 1664 i la contestació del virrei del dia 19: ACA, Consell d'Aragó, lligall núm. 762, exped. núm. 59.

${ }^{16}$ Es tracta d'una consulta manuscrita que, per estar incompleta, manca de data, però que es pot situar entre mitjan 1688 i el final de 1690 (Fuster, 1827: I, 251).

${ }^{17}$ En qualsevol cas, ja no era possible a partir del moment en què passà a servir l'ofici de regent del Consell d'Aragó en l'any 1671, per incompatibilitat manifesta.

${ }^{18}$ Joan Baptista Bravo i del Vado havia cursat els estudis de cànons a l'Estudi General de València fins a arribar a obtindre-hi el doctorat i, d'una altra banda, es va ordenar prevere. Entre 1662 i 1663 va ocupar com a substitut de Joan Jeroni Iranzo la pabordia primària de lleis, a l'oposició de la qual es presentà en aquest últim any, i també a una altra de cànons, però sense obtindre'n cap de les dues (Felipo, 1991: 310, 450, 454; Graullera, 2003: 158-159). El fracàs acadèmic probablement el decidí a impulsar la carrera com a advocat, que el va portar a Madrid dos anys després. En 1669 ja era l'advocat que la ciutat tenia a la cort reial per a la gestió dels seus assumptes.
} 
del municipi. En aquell moment, i després d'un llarg segle d'anades i tornades, el Consell ja havia comprovat que era necessari acabar els treballs de la compilació a Madrid, atés que els que tenien lloc al cap i casal del regne no finalitzaven mai... Bravo semblava conéixer bé el dret valencià - les al·legacions que s'han conservat així ho demostren - i la seua formació jurídica era adient per al treball; presentava, per tant, un perfil idoni per a l'interés dels regents, considerant la dificultat de trobar a la capital un furista expert. L'advocat, per la seua part, rebria una gratificació suplementària i podria mantindre's prop del Consell, sens dubte un al-licient per a l'exercici professional. Tampoc la ciutat, que ocupava la sindicatura del braç reial en les Corts, veuria amb mals ulls que el seu lletrat s'ocupara d'una matèria tan important per al regne.

Bravo relata - sense especificar-ne una data exacta - que la reina regent li cometé el treball, detingut a la mort del paborde Morlà, i el gran esforç que li havia suposat col·locar en les seues rúbriques 2.437 furs i actes de Cort ubicats en el volum d'Extravagants o en els quaderns impresos de les Corts de 1547 a 1645. Explicava també que, de tots els furs que no va poder col-locar en les rúbriques, havia format tres llibres que s'afegien als nou que ja hi havia, com havia fet Justinià en el Codi, creant així 45 rúbriques noves. El treball l'havia desenvolupat sense ajuda de costa, i perdent la vista per l'esforç —en aquell moment ja era cec- - Amb la plaça de cavaller podria subvenir les necessitats derivades de la ceguesa i seguir l'obra - que ja tenia començada- de dos repertoris, un de tots els furs i capítols de Cort per abecedari i l'altre «de notar los privilegios que pertenezen a las rúbricas de los Fueros para que con mayor facilidad y descanso puedan hallarse los que pertenecen a cada una dellas, lo que es de mucho travajo por estar por reynados y contener muchos de los Privilegios diferentes materias».

El Consell va indicar al rei que els mèrits de Bravo eren certs i recomanà la concessió d'allò que demanava; però va establir com a condició que acabara la compilació en la part que faltava i, a més, que fera una llista dels furs revocats per tal de llevar-los del text final i imprimir-los en un volum separat, com s'havia fet en les recopilacions de Catalunya i Aragó. ${ }^{19}$ Però el monarca no va accedir i demanà als regents que buscaren una altra gràcia més convenient, la qual cosa va detindre els treballs que faltaven per completar. Mesos després, Bravo tornà a insistir, exigint la plaça de cavaller: «la recompença que en términos de gratitud y justicia merece el dicho trabajo en que gastó diez y hocho años de continua aplicaçión y más de seiscientos peços en amanuençes espertos en la Lengua Valenciana (y por esso más costosos en esta Corte) porque para reducir a la perfección que tiene la obra uvieron de aserçe muchas copias y traslados». Però el Consell, tot i ponderar el volum d'un treball que, com reconeixia, li havia causat la ceguesa, demanà novament que l'acabara. ${ }^{20}$ Pel que sabem, en la tasca va tindre l'ajuda de Carles Gisbert, un notari de València que vivia a Madrid i que va assumir la confecció d'un sumari de tots els furs agrupats per rúbriques, i aquestes col·locades per ordre alfabètic. ${ }^{21}$ Una altra circumstància que contribuí al retardament de la recopilació va ser la falta d'una còpia autèntica i fidedigna dels furs i altres normes aprovades a València en les Corts de 1645. Tot i que Joan Baptista Bravo va ser substituit com a advocat de la ciutat

\footnotetext{
${ }^{19}$ Consulta de 8 de novembre de 1685 en ACA, Consell d'Aragó, lligall núm. 925, exped. núm. 62.

${ }^{20}$ ACA, Consell d'Aragó, lligall núm. 928, exped. núm. 42.

${ }^{21}$ Aquest sumari es conserva en una obra doble a la Biblioteca Nacional de Madrid, Manuscrit 457.
} 
per Vicent Tomàs Torres l'any 1684 a causa de la incapacitat que li causava la ceguesa, sembla que no deixà de la mà la tasca de la recopilació fins a la seua mort, l'any 1695. El fet és que, a les acaballes del segle XVII, era ja una obra pràcticament enllestida.

El canvi de dinastia, produït l'any 1700, va ser considerat pels estaments com una bona oportunitat per a portar-la a una reunió de Corts que es jutjava segura ${ }^{22}$-més encara quan el nou monarca convocà les d'Aragó i Catalunya en 1701- i aprovar-la així públicament perquè tinguera un valor oficial, superant el caràcter privat de totes les recopilacions anteriors. El lliurament dels papers de la compilació, reclamat des de la capital a un dels regents valencians del Consell d'Aragó, el jurista Joan de la Torre i Orumbella, va ser diligenciat al novembre d'aquell any. El 21 de gener de 1702, en un acte solemne, Josep, germà del regent, que acabava de ser nomenat bisbe d'Oriola i es trobava de camí per a prendre'n possessió, dipositava la compilació al Palau del Real a disposició del virrei, el marqués de Villagarcía. L'acta del lliurament, en què tan interessat estava el regent De la Torre, constitueix una magnífica descripció d'aquella obra, hui perduda, i que a penes hem començat a conéixer molt recentment:

Su Exa. y las tres Reales Salas confesaron haver recibido de dicho señor Don Juan por mano y disposición del señor D. Joseph de la Torre y Orumbella, Obispo de Orihuela, su hermano, y haver dexado custodiados en el Archivo que está en la Real Sala de Gobierno (...) los papeles siguientes: Primeramente un libro manuscrito en foleo con cubiertas de pergamino intitulado en el primer fóleo De nova fororum Regni Valentiae recopilatione, que contiene 387 fojas, y concluie la última en la página 2 del fóleo 387 de Çerdonibus rúbrica 14.= Íttem, quareintaynueve quadernos manuscritos de la nueva recopilación de los fueros y autos de corte de Valencia, estando los fueros y privilegios para que se saquen con facilidad, y un quaderno del índiçe, que es copia del Libro anteçedente, y componen todos cinqüenta quadernos.= Íttem otro volumen manuscrito, que se intitula reportorio de la nueva recopilación de los fueros y autos de Corte de este Reyno por orden Alphabético, y contiene treintaycinco quadernos, y al fin hay sueltos cinco quadernos más, de las letras desde la $\mathrm{H}$, hasta la $\mathrm{Y}$ inclusive, que se han de añadir en sus lugares.= Otro volumen manuscrito intitulado: Reportorio sacado de Ginart, que contiene 200 folios inclusive. $=$ Íttem otro volumen manuscrito intitulado Summario de los capítulos de las Cortes aplicados a cada rúbrica de los fueros para colocarse en cada una de ellas, que contiene 135 fóleos.= Íttem otro quaderno manuscrito que se intitula Capítulos, o autos de Corte, que se omitieron y no están colocados baxo las rúbricas del primer Libro de los Fueros de Valencia, que contiene 14 folios. Y para que conste doy la presente firmada de mi mano, y sellada con el Real Sello de esta Real Cancellería. En Valencia a 21 de Henero 1702. Eusebio de Benavides. ${ }^{23}$

Un mes després, el 20 de febrer, els electes per a les Corts, constituïts en junta, van demanar al virrei aquests papers de Joan Baptista Bravo, «que eren la recopilació dels furs», per a completar l'obra, sotmetre-la a l'aprovació dels braços i després a la del rei en la solemne reunió que s'esperava. El 6 de març acordaren que fora Josep Ortí i Moles,

\footnotetext{
${ }^{22} \mathrm{Al}$ novembre de 1701, una junta ad hoc dels estaments va començar a preparar una eventual reunió de Corts, com recull Carmen Pérez Aparicio (2008: I, 184201).

${ }^{23}$ ARV, Reial Cancelleria, 595, f. 168r169r. Va ser també Carmen Pérez Aparicio la primera a cridar l'atenció sobre la importància de la troballa.
} 
doctor en lleis i secretari dels estaments i de la mateixa Junta d'Electes per a les Corts, qui es fera càrrec d'acabar la recopilació, que — com reconeixien els síndics - a la mort de Bravo estava molt avançada, gairebé conclosa. Però en demanar els papers al virrei, aquest contestà que els havia rebut per reial ordre i que no els podia lliurar sense una nova prescripció del monarca; tot i això, es va oferir a escriure al Consell d'Aragó amb la pretensió dels estaments. Així, a començament d'abril arribà l'ordre de fer una còpia del material, mentre la Junta llegia i repassava els furs aprovats en 1645. Per fi, el 15 de maig de 1702 es va rebre una reproducció dels cinquanta quaderns manuscrits a què feia referència el segon ítem de l'acta de lliurament; en conseqüència, els papers van romandre en la secretaria dels estaments a disposició de Josep Ortí, qui havia de tancar la compilació.

Les notícies acaben pràcticament ací. Sabem pels fons documentals de la sèrie «Reial» de l'Arxiu del Regne de València que la Junta va continuar reunint-se fins al final de novembre de 1702. Però les Corts valencianes no arribaren a aplegar-se, ja que les urgències del nou monarca eren diferents i venien marcades pel desenvolupament de la guerra, primer a Itàlia i després a la península Ibèrica. També el regne es va veure immers en aquelles mateixes urgències, de manera que l'assumpte de la recopilació es va veure abandonat fins a un moment més propici. Però l'abolició dels furs el 29 de juny de 1707 ajornà aquell moment per sempre més. El manuscrit de la compilació va córrer, d'alguna manera, una sort semblant. No pareix que s'haja conservat l'exemplar original entre els fons de la Cancelleria Reial, a l'Arxiu del Regne - almenys les cerques fetes no han donat resultat-; ni tampoc la còpia feta pels estaments, en el seu propi fons documental. Possiblement van ser destruïts, o bé enviats a Madrid en algun dels intents de recuperació dels furs del segle XVIII; o potser acabaren en la biblioteca particular d'algun jurista, com ara la de la família Borrull. La cerca, de tota manera, haurà de continuar.

\section{La vitalitat del dret foral valencià a través de les seues compilacions}

Més enllà del fet que trobem un dia el manuscrit del codi, o en comprovem documentalment la desaparició, cal destacar alguns dels elements històrics i jurídics que el descobriment de l'existència d'una compilació valenciana completa i finalitzada a les acaballes del segle XVII mostren. En primer lloc, sorprén el paper protagonista que assumeix la monarquia - el Consell d'Aragó- en l'impuls dels treballs. ${ }^{24}$ Fins ara, la teoria tradicional sostenia que la Corona es desentenia de les recopilacions que s'elaboraven als territoris orientals de la península. La causa la trobaríem en el fet que l'estructura i composició d'aquestes obres es basava en el dret propi dels regnes i deixava de banda les normes usuals del rei en l'edat moderna (pragmàtiques, cèdules, reials ordres, etc.). Per això proliferaven les compilacions cronològiques, tècnicament més imperfectes, i les privades, sense valor ni reconeixement oficial. Però, en el cas valencià les Corts volgueren superar l'obra particular del notari Francesc Joan Pastor i així ho van demanar al rei en les Corts de Montsó de 1564; el fracàs inicial dels treballs de Pere Jeroni Tarazona va

\footnotetext{
${ }^{24}$ La correspondència entre els estaments, el virrei i el Consell d'Aragó conservada a l'Arxiu del Regne de València al voltant de l'enviament de la recopilació a València demostra de forma ben palesa el paper ben reduït que jugaven els primers en aquesta qüestió.
} 
portar a la realització de noves peticions en les Corts de 1604 i 1626. A mitjan segle XVII, vora cent anys després d'aquella petició inicial, i en comprovar la incapacitat de les institucions valencianes - braços, estaments, Diputació del General- per a portar a terme la tasca, el Consell se'n va fer finalment càrrec. El fet que fóra la Corona la que impulsara aquests treballs obliga a reconsiderar l'afirmació del desinterés de la monarquia per les recopilacions aragoneses; també a afegir una funció més a les que habitualment considerem com a pròpies del Consell d'Aragó abans de la seua extinció; i, per últim, a reflexionar sobre el pretés caràcter «constitucionalista» que tindrien les recopilacions modernes, un concepte que no encaixa massa bé amb el fet que siga la mateixa monarquia la que desenvolupe aquests projectes.

En segon lloc, l'existència de la compilació demostra la vitalitat del dret valencià a les acaballes de l'època foral. Algunes opinions sostenen que l'ordenament jurídic del regne es trobava en una situació de crisi, de manera que l'abolició de 1707 a penes trobaria resistència a causa de l'esmentada debilitat i, per tant, tampoc no hauria tingut una incidència apreciable entre la població d'aleshores. Però, enfront d'aquestes interpretacions, que habitualment parteixen de la situació de llanguiment de les Corts valencianes durant el segle XVII, cal ressaltar la vitalitat d'altres fonts jurídiques, com ara la doctrina, la pràctica o el mateix costum. ${ }^{25}$ La frustrada compilació de 1702 ve, doncs, a unir-se a una gran quantitat d'obres que en aquella època s'ocupaven del dret propi i que mostren una vitalitat notable del nostre dret d'aleshores, molt allunyada d'una presumpta situació de crisi. El mateix fet d'haver d'afegir tres llibres nous amb 45 rúbriques noves comprensives de centenars de furs i capítols en resulta ben expressiu. Per cert, que fóra el Consell la institució que s'ocupara de l'obra també podria explicar els canvis en la seua composició, ja que, en concret, la incorporació d'aquells llibres i rúbriques noves, o altres alteracions menors com la quasi desaparició de l'apartat d'Extravagants, trencaven definitivament l'estructura tradicional jaumina, bo i atorgant al còdex un aire diferent.

En darrer terme, la compilació demostra la posició de centralitat que tenia la legislació de Corts - furs, capítols i actes de Cort- en el sistema jurídic foral i la importància que tenia tant per a la Corona com per als estaments que representaven al regne, per damunt d'altres normes, sobretot les del rei - pragmàtiques i cèdules - que o no es recopilaven, $\mathrm{o}$ eren reunides en altres reculls monogràfics. No obstant això, els juristes que s'hi ocupen també solen fer referència, encara que siga de manera collateral, a l'altra font cabdal de l'ordenament jurídic valencià: el privilegi (Álvarez Cora, 2005: 124 i ss). En aquest sentit, posteriors estudis ens hauran de permetre aprofundir en el paper que el dret tenia entre els mecanismes de govern del regne en el darrer període foral. La comparació amb els moviments recopiladors d'altres territoris de la Corona d'Aragó també serà profitosa. En tot cas, el que cada vegada resulta més clar segons progressem en el coneixement d'aquesta època és que les afirmacions de caràcter taxatiu — sobretot aquelles que fan una lectura molt en negatiu del període $-{ }^{26}$ hauran de ser revisades en el futur.

\footnotetext{
${ }^{25}$ Sempre hi ha algú que prefereix seguir instal-lat en el mite imaginari, siga perquè és un simple ignorant, $\mathrm{o}$ perquè li ajusta millor al seu relat, aparentment plausible - la postveritat historiogràfica-, però fal-laç al cap i a la fi. Vegeu, per exemple, Masferrer (2015: 243-272). Més d'un lustre després de la troballa, segueix ignorant l'existència del text de 1702. Aquesta circumstància invalida bona part del seu treball per la manca de rigor.

${ }^{26}$ Per totes, i com a exemple, la que fa Manuel Santana (2007: 375423, especialment 397 i ss).
} 


\section{BIBLIOGRAFIA}

Alanyà, L. (1515): Aureum Opus Regalium Privilegiorum Civitatis et Regni Valentiae, València, Diego de Gumiel.

ARINYÓ, G.L. (1482): Furs e ordinacions fetes per los gloriosos reys de Aragó als regnícols del Regne de València, València, Lambert Palmar.

Febrer Romaguera, V. (2000a): «Catedráticos de leyes y literatura jurídica en la universidad de Valencia anterior a la provisión de las cátedras pavordías (1499-1589)», CIAN. Revista de historia de las universidades, 3, 31-70.

— (2000b): «Pere Joan de Capdevila, catedrático y abogado (hc.1495-1558). Biografía y estudio bibliográfico de su biblioteca jurídica», Cuadernos de documentación multimedia, 10, 197-238.

FeliPo, A. (1991): La Universidad de Valencia durante el siglo XVII (16111707), València, Publicacions de la Universitat de València.

Fuster, J.P. (1827): Biblioteca Valenciana, València, José Gimeno.

García Edo, V., V. Graullera, N. Bas (2002): El llibre de dret valencià a l'època foral, València, Biblioteca Valenciana.

Graullera, V. (2003): Juristas valencianos del siglo XVII, València, Biblioteca Valenciana.

Masferrer, A. (2015): «Del fracaso recopilatorio a la pérdida definitiva del derecho foral valenciano (1707-1804)», Revista de Dret Històric Català, 14, 243-272.

Oleart, O. (2004): «El capítulo 24 de las Cortes de Monzón de 1585 y la elaboración de la recopilación catalana de 15881589. Datos para su historia», Initium, 9, 223286.

Palao, F. J. (2007): «Un proyecto de recopilación de "Furs de València" del siglo XVII», Derecho, historia y universidades. Estudios dedicados a Mariano Peset, 2 vols., València, Publicacions de la Universitat de València, II, 359368.

- (2013): «Constitucionalisme i recopilació del dret en la València foral: el cas de la compilació inèdita de 1702», El Compromiso de Caspe (1412), cambios dinásticos y constitucionalismo en la Corona de Aragón, Saragossa, Ibercaja, 597-605.

Pastor, F.J. (1547-1548): Fori Regni Valentiae, València, Johan Mey.

Pérez Aparicio, C. (2008): Canvi dinàstic i Guerra de Successió. La fi del Regne de València, 2 vols., València, Tres i Quatre, I, 184201.

Peset, M. (1971): «Observaciones sobre la génesis de los Fueros de Valencia y sobre sus ediciones impresas», Ligarzas, 3, 4784.

Santana, M. (2007): «La Nueva Planta y la abolición del Derecho valenciano», J. A. Escudero (coord.), Génesis territorial de España, Saragossa, El Justicia de Aragón, 375423.

TARAZona, P. J. (1580): Institucions dels furs y privilegis del Regne de València, València, Pedro de Huete. Tomás y Valiente, F. (1986): Manual de Historia del Derecho Español, Madrid, Tecnos (4a ed.).

\section{BIONOTA}

\section{Francisco Javier Palao Gil}

És llicenciat i doctor en Dret a la Universitat de València, on també es va llicenciar en Geografia i Història. En l'actualitat exerceix com a professor titular d'Història del Dret a la mateixa universitat, a més de ser director de la Càtedra Institucional de Dret Foral Valencià i degà de la Facultat de Dret. Ha format part, com a vocal, de la Comissió de Codificació Civil Valenciana al llarg d'una quinzena anys i les seues línies d'investigació s'han centrat en l'estudi de la tradició jurídica i les doctrines polítiques de l'edat moderna, la història del dret de l'antic Regne de València i la història de les universitats. Ha publicat nombrosos articles i ponències sobre aquestes matèries i en l'actualitat prepara una monografia sobre el Foralisme en temps de privació: els valencians davant l'abolició dels furs. 